\title{
Evaluating the effectiveness of a public awareness campaign as a conservation intervention: the saiga antelope Saiga tatarica in Kalmykia, Russia
}

\author{
Caroline Howe, Olga Obgenova and E. J. Milner-Gulland
}

\begin{abstract}
We carried out an in-depth analysis of a media campaign designed to raise awareness of the ecology and conservation of the Critically Endangered saiga antelope Saiga tatarica in the Pre-Caspian region of Russia. We carried out 250 semi-structured interviews in eight villages. The effectiveness of the campaign was assessed using change in opinion over the previous 3 years as an attitudinal indicator and amount pledged for saiga conservation as a measure of behavioural intention. The campaign induced positive changes in attitudes and behavioural intention. Reinforcement was important, with people's retention of information about saiga conservation from the campaign being positively correlated with their level of ecological knowledge about the species. Similarly, behavioural intention towards the saiga was more likely to be positive in individuals who had a high level of exposure to the species and/or had been subject to two or more different conservation interventions. Level of attitudinal change was dependent on an interaction between the date when the media campaign was carried out and the age of the respondent. We conclude that public awareness campaigns, if designed to take into account the socio-demographics and cultural background of the target audience, can be an effective method of improving attitudes towards conservation.
\end{abstract}

Keywords Attitudes, education, indicators, media, opinions, Saiga tatarica, success, willingness-to-pay

This paper contains supplementary material that can be found online at http://journals.cambridge.org

\section{Introduction}

Tucation is often viewed as an unalloyed good and

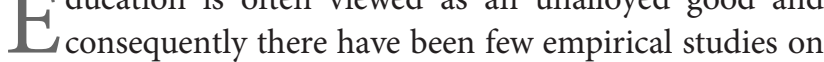

Caroline Howe (Corresponding author) ${ }^{*}$ and E.J. Milner-Gulland Department of Life Sciences and Centre for Environmental Policy, Imperial College London, Exhibition Road, London, SW7 2AZ, UK. E-mail c.howe.01@ cantab.net

Olga Obgenova Centre for Ecological Projects of the Republic of Kalmykia, Elista, Republic of Kalmykia, Russian Federation

${ }^{*}$ Also at: 6 Rathen Road, Manchester, M20 4GH, UK

Received 21 July 2010. Revision requested 18 February 2011. Accepted 26 May 2011. the costs and benefits of different forms of environmental education. Environmental education is often only considered in terms of formal learning undertaken in schools or higher education. However, Agenda 21, drawn up at the Rio Earth Summit in 1992, states that both formal and nonformal education are indispensable to changing people's attitudes (UNESCO, 1992). Environmental education should be considered to include public awareness-raising (e.g. media campaigns), school environmental clubs and transfer of indigenous knowledge as well as training and formal education.

Studies quantifying the effect of formal education on conservation outcomes are limited and explore the influence of existing, formal educational provision rather than targeted educational programmes. Generally they agree that it has a beneficial effect (Godoy \& Contreas, 2001; AlixGarcia, 2007) but the effect is non-linear and there is a point of inflection beyond which the returns from education decrease (Van, 2003). It has been argued that non-formal education is a necessary supplement to formal education (Weladji et al., 2003) and that it may have a more immediate impact and be better able to absorb and utilize local knowledge than traditional, formal education (Nyhus et al., 2003). Studies exploring non-formal education in the agricultural field have shown that while formal education is not a significant factor in agricultural productivity, nonformal education is (Kalirajan \& Shand, 1985; Parra-Lopez et al., 2007).

For an education programme to contribute to conservation success a change in attitudes, behavioural intention and, ultimately, behaviour has to occur. Education has been shown to influence attitudes. A study on manatee Trichechus manatus latirostris conservation showed that greater knowledge about manatees was positively correlated with support for manatee protection (Aipanjiguly et al., 2002). Formal education level, even when not specifically tailored to conservation, also correlates with positive attitudes to conservation (Mehta \& Heinen, 2001). For example, undergraduates' formal knowledge of conservation biology correlates with the environmental opinions they hold (Caro et al., 1994).

However, knowledge of environmental issues alone are not sufficient to elicit positive environmental behaviour (Hungerford \& Volk, 1990; Palmer \& Birch, 2005). Inferring a causative relationship between educational initiatives and behavioural changes through an attitudinal assessment requires careful consideration of potentially confounding 
social, economic and cultural factors (Holmes, 2003). The Theory of Planned Behaviour states that human action is governed by behavioural beliefs, normative beliefs and control beliefs that interact to give rise to perceived behavioural control (Ajzen, 1991), where a belief is an individual's opinion about an object and, where a particular behaviour has occurred, the consequences of that behaviour for the object (Bateman \& Willis, 2001).

The north-west Pre-Caspian region of the Russian Federation is one of the poorest regions of the country. The dissolution of the USSR in 1991 resulted in high levels of unemployment in the area (Grin, 2000). The consequent poverty and collapse in hunting controls drive the illegal hunting of the saiga antelope Saiga tatarica (Kühl et al., 2009). The saiga is a nomadic ungulate of the Central Eurasian rangelands, hunted both for its horn, used in traditional Chinese medicines, and for meat for local consumption (Milner-Gulland et al., 2001). Post-Soviet over-hunting led to a dramatic population reduction from $>_{1}$ million to $<50,000$ (Milner-Gulland et al., 2001) and in 2002 the species was categorized on the IUCN Red List as Critically Endangered (IUCN, 2010).

In 1990 the Chernye Zemli Biosphere Reserve was established in the Autonomous Republic of Kalmykia, followed by the Stepnoi Reserve in the neighbouring Astrakhan Province in 2000. Both reserves undertake monitoring and protection of the saiga, emphasizing traditional so-called fences-and-fines conservation. In 2003 a UK Darwin Initiative saiga project began in Kalmykia, including biological research and social surveys, to elucidate the prevalence and drivers of poaching, and public engagement activities. This was followed in 2006 by a DEFRA-funded Small Environmental Projects Scheme to provide cows to two villages in Kalmykia. The aim of this project was to provide alternative livelihoods for the poorest members of society and also involved a general media campaign in local newspapers and TV that reached the rest of Kalmykia.

The Darwin Initiative project was awarded post-project funding in 2006 to examine the effect of the preceding conservation interventions on attitudes and to continue the public awareness campaign in Kalmykia. The villages in neighbouring Astrakhan province are geographically, administratively and ethnically separated from the Kalmykian villages, and throughout the period were exposed only to the traditional conservation activities of the Stepnoi Reserve. Because of the pervasive nature of media in the region, by controlling for potential leakage and potentially confounding socio-economic and cultural factors we are able to test the hypothesis that media-based public awareness campaigns are an effective tool for producing positive, long-term attitudinal changes and behavioural intentions towards conservation. This study analyses the effectiveness of public awareness campaigns carried out in this region over the period 2003-2007. The aim was to understand how such interventions work in practice and to provide useful guidelines for the effective use of future public awareness campaigns for environmental conservation.

\section{Study area}

This study was conducted in eight villages in southern Russia (Fig. 1). Four villages in the Autonomous Republic of Kalmykia (Utta, Erdnevskiy, Molodozhnye and Adyk) were exposed to a targeted media campaign, through regional and local papers and local TV. Two villages in Kalmykia (Khulkhutta and Tavn-Gashun) were targets for social engagement and also exposed to the media campaign. By contrast, two villages in the Liman region of Astrakhan Province (Bacy and Zenzeli) were exposed only to the Stepnoi Reserve's traditional fences-and-fines conservation (Table 1). The villages ranged in size from 415 people (Municipal Administration of Tavn-Gashun, 2007) to 3,112 people (Municipal Administration of Zenzeli, 2007). Unemployment was generally high and employment was in the livestock sector or in unskilled and temporary work.

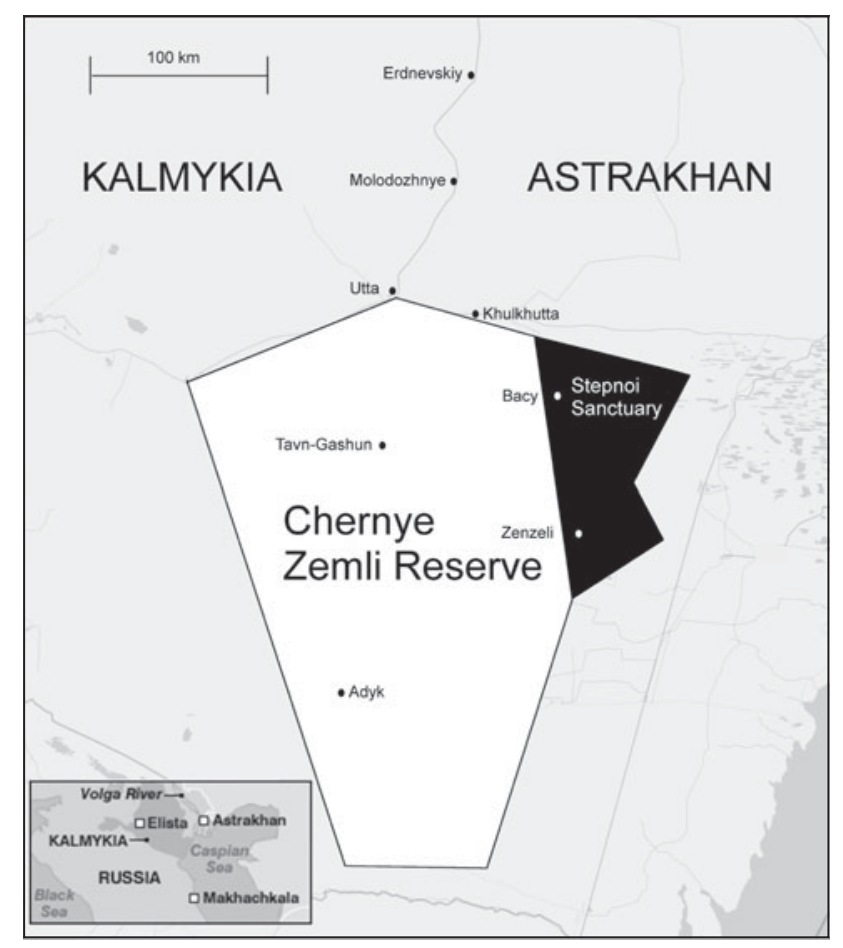

FIG. 1 The location of Kalmykia and Astrakhan within the Russian Federation showing the eight study villages. The white shaded area indicates the Chernye Zemli Reserve in Kalmykia and the black area the Stepnoi Sanctuary. Utta, Khulkhutta, Tavn-Gashun, Adyk, Erdnevskiy and Molodozhnye were exposed to the media campaign, Khulkhutta and Tavn-Gashun were involved in the social engagement project, and Bacy and Zenzeli were under traditional conservation intervention (adapted from OpenStreetMap, 2011). 
TABlE 1 Conservation interventions for the saiga antelope Saiga tatarica carried out between 1990 and 2006 in Kalmykia and Astrakhan (Fig. 1).

\begin{tabular}{|c|c|c|c|}
\hline Conservation programme & Date & Location & Main funding body \\
\hline Using saiga antelope to improve rural livelihoods & $2003-2006$ & Khulkhutta, Tavn-Gashun & Darwin Initiative (DEFRA $\left.{ }^{1}, \mathrm{UK}\right)$ \\
\hline Rotating cows project & 2006-onwards & Khulkhutta, Tavn-Gashun & $\begin{array}{l}\text { Small Environmental Projects } \\
\left.\text { (DEFRA }^{1}, \mathrm{UK}\right)\end{array}$ \\
\hline $\begin{array}{l}\text { Evaluating approaches to public engagement with } \\
\text { saiga conservation }\end{array}$ & $2006-2007$ & $\begin{array}{l}\text { Utta, Erdnevskiy, } \\
\text { Molodozhnye, Adyk }\end{array}$ & Darwin Initiative (DEFRA $\left.{ }^{1}, \mathrm{UK}\right)$ \\
\hline $\begin{array}{l}\text { Chernye Zemli Reserve: support \& capacity } \\
\text { building }\end{array}$ & 1990-onwards & Kalmykia & Russian Federation, UNESCO ${ }^{2}$ \\
\hline $\begin{array}{l}\text { Stepnoi Sanctuary: anti-poaching \& population } \\
\text { monitoring }\end{array}$ & 2000-onwards & Astrakhan & Atrakhan Province, INTAS ${ }^{3}$ \\
\hline
\end{tabular}

${ }^{1}$ Department for Environment, Food and Rural Affairs

${ }^{2}$ UN Educational, Scientific and Cultural Organization

${ }^{3}$ International Association for the promotion of cooperation with scientists from the independent states of the former Soviet Union

\section{Methods}

\section{Data collection}

Data were collected during September-October 2006, with 250 respondents chosen using systematic transects of each village. This methodology could potentially be biased if the houses are not representative of the village as a whole but because of time constraints it was the best method to obtain as random a sample as possible. Depending on size, 25-40 households $(5-35 \%$ of the resident population) were interviewed in each village. This was the minimum sample size to ensure adequate power in subsequent analyses (Kirk, 1995). The representativeness of the sample was validated by comparison with a previous study in the same region (Kühl et al., 2009) and with official demographic statistics.

Questionnaires contained structured and semistructured questions to obtain breadth and depth of information (Bernard, 2002). Questions assessed interviewee exposure to the saiga, knowledge of population trends and local and national conservation projects. Respondents were also asked to reply to three statements regarding the saiga and its conservation to gauge their general opinion of the species and conservation. Amount pledged for conservation of the saiga was used a measure of behavioural intention to contribute to conservation (Mitchell \& Carson, 1989; Bateman et al., 2002; Howe et al., 2011). A closed payment ladder, coupled with a voluntary payment scenario, was used to elicit amount pledged (Mitchell \& Carson, 1989; Bateman et al., 2002). The scenario used to elicit amount pledged was developed to be locally appropriate, taking into consideration the means of payment and form of action to be undertaken (Fischhoff \& Furby, 1988). Respondents making zero bids were asked to give a reason based upon a list developed in consultation with local colleagues. Interviews were conducted in person by Caroline Howe $(\mathrm{CH})$ and Ruslan Medzhidov (RM), together with a trained translator (Appendix 1).
Data analysis

People's knowledge about saiga conservation projects in the area (conservation knowledge) and whether they remembered receiving public awareness materials were used as response variables to explore how knowledge was acquired and retained. Asking interviewees whether they remembered receiving materials allowed us to ascertain the impact of the targeted media campaign taking into consideration information already available. Their change in opinion towards the saiga and its conservation over the last 3 years (opinion change over time) and the amount pledged for saiga conservation were used as response variables representing attitudes and behavioural intention respectively (Howe et al., 2011). The explanatory variables were the type of intervention (media campaign, social engagement + media campaign, and traditional conservation), ethnicity, wealth, village, geographical area (Kalmykia or Astrakhan), level of formal education, exposure to the saiga, residence time in the village and knowledge about saiga population status (population knowledge). Those who remembered receiving public awareness materials were also asked openended questions on when they remembered receiving the materials (date), what media format (media) they came in (e.g. newspaper or television), subject matter (subject), and whether the materials had had an immediate effect (did the respondent recall undergoing a change in awareness upon receiving the materials). Several of these variables were scored subjectively (Appendices $1 \& 2$ ).

Three factors were spatially confounded: administrative area (Kalmykia and Astrakhan), village and conservation intervention. Area did not provide any explanatory power over and above village and intervention, and was therefore not used in the final models. A priori, the inclusion of ethnicity into the model may take into account possible area effects because the Kalmykian villages are dominated by ethnic Kalmyks and the Astrakhan villages by ethnic Russians, while being less confounded with intervention. 
TABLE 2 Interviewee responses to a series of statements regarding the saiga and its conservation.

\begin{tabular}{|c|c|c|c|c|c|}
\hline Statement & $\begin{array}{l}\text { Strongly } \\
\text { agree }\end{array}$ & Agree & Disagree & $\begin{array}{l}\text { Strongly } \\
\text { disagree }\end{array}$ & $\begin{array}{l}\text { Don't } \\
\text { know }\end{array}$ \\
\hline I have more important things to think about than the future of the saiga antelope & 2 & 57 & 32 & 0 & 8 \\
\hline If the saiga were lost from Russia I would not mind & 0 & 5 & 62 & 25 & 7 \\
\hline $\begin{array}{l}\text { The saiga should be protected for future generations even if that means making } \\
\text { sacrifices now }\end{array}$ & 72 & 22 & 0 & 3 & 3 \\
\hline
\end{tabular}

To separate the effect of conservation intervention and village, linear mixed effects (LME) models were used with intervention and village treated as random effects. Because of our particular interest in the recalled effects of public awareness materials whether people remembered receiving materials, or aspects of this variable such as date or subject, were always included in the saturated model. By treating intervention and whether people remembered receiving materials and/or village as fixed and random effects respectively allowed us to compare villages exposed to the media campaign with those not exposed whilst taking potential leakage effects (non-targeted media) into consideration.

We fitted an LME model using the lme4 package in $R$ ( $\mathrm{R}$ Development Core Team, 2008) with binomial errors for whether or not people remembered receiving some form of media material and an LME model with binomial errors for whether or not people had some knowledge of saiga conservation projects in the region. Because of the potential confounding effects of other explanatory variables on attitudes and opinions (Holmes, 2003; Howe et al., 2011), the amount pledged for saiga conservation, as a measure of behavioural intention, and opinion change over the last 3 years, were modelled against whether people remembered receiving public awareness materials (instead of using a direct comparison between villages exposed to the media campaign with those not exposed). The models were then re-run with only those people who had remembered receiving information, to investigate the effect of subject matter, date of receiving public awareness materials, and medium. Opinion change was coded as +1 for those who had changed from a negative or indifferent position to a positive one and as o for those who had remained negative or indifferent. Those remaining positive throughout were excluded. A generalized linear model (GLM) with binomial errors was used, as the random effects were not significant (using the $n l m e$ package in $R$ ). For amount pledged for saiga conservation an LME with Gaussian errors was used, using $\log$ of amount pledged. The random effect variables, intervention and village, explained 5.03 and $2.76 \%$ of the variation respectively, and thus the LME was retained.

Explanatory variables to include in each model were chosen first by using exploratory statistics to eliminate any highly correlated variables and then by using a tree model (Crawley, 2007). Two-way interactions between explanatory variables that a priori could be of interest were added. Stepwise deletion was carried out based on non-significant $\mathrm{P}$ values (5 and 10\%), with largest $\mathrm{P}$ values and two-way interactions removed first. Non-significant main effects were removed only if not involved in two-way interactions. After each removal of each variable the model was checked with an ANOVA or F-test (where overdispersion occurred) to assess the significance of the subsequent increase in deviance (Crawley, 2007). Fixed effects were analysed using maximum likelihood and random effects using restricted maximum likelihood. In those cases where the random effect explained little or no variation, a GLM was tested against the LME, using ANOVA, and accepted as the minimum adequate model if there was no significant difference between the two models. Residuals versus fitted values plots were used for informal exploration and the Breusch-Pagan test used to test for heteroscedasticity.

\section{Results}

\section{Public attitudes}

Two-thirds of respondents agreed that they had more important things than the saiga to think about, although they were more likely simply to agree rather than strongly agreeing with this statement. However, $89 \%$ said they would mind if the saiga was lost from Russia and 94\% strongly agreed that the saiga should be protected now, for future generations (Table 2).

Forty-two percent of interviewees had always had a positive opinion towards the saiga and saiga conservation and had retained this over time, $47 \%$ had changed from being either negative or indifferent towards the saiga to positive, and $12 \%$ remained indifferent or negative over the same period of time. When asked to pledge an amount for saiga conservation, only $18 \%$ of respondents bid a zero value. Of those who made a bid, the amount pledged was RUB 141-630 (USD 5.26-23.52, respectively, at 2006 rates).

\section{Who is receiving and remembering public awareness materials?}

Seventy-six percent of those interviewed remembered receiving some form of public awareness. Of those exposed 
TABLE 3 Minimum adequate model (fit by GLM with binomial errors) for 'remembered having received public awareness materials' $(n=250)$. Significant explanatory variables are intervention and exposure to saigas. Exposure to the saiga is an ordered factor and intervention is nominal. Estimate of the nominal factor represents differences in effect between intervention types, where the media campaign is the baseline.

\begin{tabular}{|c|c|c|c|c|}
\hline \multirow[b]{2}{*}{ Parameter } & \multicolumn{4}{|c|}{ 95\% confidence interval } \\
\hline & Estimate & SE & $z$-statistic & $\mathrm{P}$ \\
\hline Intercept & 0.737 & 0.603 & 1.223 & 0.221 \\
\hline Intervention & -0.522 & 0.180 & -2.910 & $0.004^{* * *}$ \\
\hline Social engagement & 0.563 & 0.594 & 0.949 & 0.343 \\
\hline $\begin{array}{l}\text { Traditional } \\
\text { conservation }\end{array}$ & -1.047 & 0.347 & -3.016 & $0.003^{* * *}$ \\
\hline Exposure & 0.911 & 0.251 & 3.630 & $0.000^{* * *}$ \\
\hline
\end{tabular}

$* * *$, significant at $1 \%$

only to the media campaign $83 \%$ remembered receiving some form of media material. Ninety-three percent of those exposed to both the social engagement and media campaign said they had received some form of media material, compared to only $53 \%$ of those exposed to traditional conservation.

The minimum adequate model for whether people remembered receiving public awareness materials or not revealed that those exposed to social engagement were more likely to remember receiving public awareness materials, followed closely by those targeted by the media campaign (Table 3). The probability of remembering receiving public awareness materials increased with increasing exposure to the saiga (how recently and often they had seen the species). Ninety-eight percent of those with the highest exposure to the saiga remembered receiving public awareness materials compared to $65 \%$ of those with the lowest exposure.

The minimum adequate model for whether people had some knowledge of conservation activities in the region includes both intervention and remembering having received public awareness as significant explanatory variables, alongside knowledge about the saiga population (Table 4 ). The random effect of village explained $68 \%$ of the variation in this model, suggesting that knowledge of conservation was strongly dependent on village. Those exposed just to the media campaign were more likely to know about conservation in the region if they also had a high level of knowledge about population status. However, the conservation knowledge of those exposed to traditional conservation was unrelated to their population knowledge of saigas. All of the respondents who had been exposed to social engagement knew something about conservation and therefore population knowledge was not a significant covariate in this case.
TABle 4 Minimum adequate model (fit by LME model with binomial errors) for whether a respondent has some or no knowledge of conservation projects $(n=250)$. Significant explanatory variables are knowledge of saiga population status (population knowledge) and remembering having received public awareness information, and an interaction between population knowledge and conservation intervention.

\begin{tabular}{lrlrl}
\hline & \multicolumn{4}{l}{$95 \%$ confidence interval } \\
\cline { 2 - 5 } Parameter & Estimate & $\mathrm{SE}$ & $z$-statistic & $\mathrm{P}$ \\
\hline Intercept & -1.938 & 1.523 & -1.272 & 0.203 \\
Population knowledge & 0.798 & 0.284 & 2.812 & $0.005^{* * *}$ \\
$\quad \begin{array}{l}\text { Remembered public } \\
\quad \text { awareness }\end{array}$ & 0.940 & 0.367 & 2.561 & $0.010^{* *}$ \\
$\quad \begin{array}{l}\text { Intervention } \\
\text { Population knowledge } \\
\quad \text { intervention }\end{array}$ & 0.845 & 0.691 & 1.223 & 0.221 \\
\hline
\end{tabular}

${ }^{* *}$, ${ }^{* *}$, significant at $5 \%$ and $1 \%$, respectively

What type of information was received and when?

Those who had not been targeted by the media campaign tended to have received their information earlier than 2006 and mostly via television (Table 5). In most cases the information was about the ecology and life history of the saiga. Those exposed to the media campaign received an even coverage from both newspapers and television. However, those exposed to the social engagement (rotating cows) project remembered receiving their information most recently (i.e. in 2005 and 2006) despite conservation interventions in their villages starting in 2003. Those exposed to the media campaign alone did not generally recall receiving their information during the height of this campaign, August-October 2006, but earlier.

The results also indicate that women tended to read less about conservation than men $\left(\chi^{2}=8.986, \mathrm{P}=0.029\right.$, $\mathrm{df}=3$ ). Ethnic Russians and other nationalities (i.e. not Kalmyks) tended to receive their information via television and learnt more about ecology than other subjects $\left(\chi^{2}=9.856, \quad \mathrm{P}=0.043, \quad \mathrm{df}=4 ; \quad \chi^{2}=17.535, \quad \mathrm{P}=0.008\right.$, $\mathrm{df}=6$, respectively). However, $73 \%$ of ethnic Russians interviewed lived in villages exposed to traditional conservation, and therefore were a priori more likely to have received their information through the medium of television and on the subject of ecology.

How does public awareness affect attitudes and behavioural intention?

The immediate effect of information (whether respondents recalled undergoing a change in awareness on receiving the information) was influenced by the sex of the individual and the medium of the information $\left(\chi^{2}=4.066, \mathrm{P}=0.044\right.$, $\mathrm{df}=1 ; \quad \chi^{2}=5.914, \quad \mathrm{P}=0.049, \quad \mathrm{df}=2, \quad$ respectively). 
TABLE $5 \chi^{2}$ tests of the medium respondents recalled seeing, the subject of the material and the recalled date of receiving public awareness, for the different interventions $(n=191)$. For each intervention the most common outcomes are shown with a tick.

\begin{tabular}{|c|c|c|c|}
\hline & $\begin{array}{l}\text { Media } \\
\text { campaign }\end{array}$ & $\begin{array}{l}\text { Social } \\
\text { engagement } \\
\text { \& media } \\
\text { campaign }\end{array}$ & $\begin{array}{l}\text { Traditional } \\
\text { conservation }\end{array}$ \\
\hline \multicolumn{4}{|c|}{$\operatorname{Media}\left(\chi^{2}=31.642, \mathrm{df}=4, \mathrm{P}<0.001\right)$} \\
\hline Newspaper & $\sqrt{ }$ & $\sqrt{ }$ & \\
\hline Television & $\sqrt{ }$ & & $\sqrt{ }$ \\
\hline \multicolumn{4}{|c|}{ Subject $\left(\chi^{2}=45.190, \mathrm{df}=6, \mathrm{P}<0.001\right)$} \\
\hline Ecology & $\sqrt{ }$ & $\sqrt{ }$ & $\sqrt{ }$ \\
\hline Conservation & $\sqrt{ }$ & $\sqrt{ }$ & \\
\hline Poaching & $\sqrt{ }$ & $\sqrt{ }$ & \\
\hline \multicolumn{4}{|c|}{ Date $\left(\chi^{2}=42.844, \mathrm{df}=4, \mathrm{P}<0.001\right)$} \\
\hline $\begin{array}{l}\text { August-October } \\
2006\end{array}$ & & $\sqrt{ }$ & \\
\hline January-July 2006 & $\sqrt{ }$ & & \\
\hline 2005 and earlier & & & $\sqrt{ }$ \\
\hline
\end{tabular}

Television was reportedly a more effective medium than reading materials and men watched more television than women. Although not significant, there was a slight effect of subject matter on the direct effect of information, with ecology and conservation materials producing a more positive response than information about poaching.

Opinion change over the previous 3 years was highly influenced by remembering having received public awareness materials, with those receiving information being much more likely to become positive about the saiga and saiga conservation (Table 6). Opinion change was more likely if an individual also reported that the information had had an immediate effect when it was received. Once again the occurrence of reinforcement was observed, with opinion change also being strongly influenced by an individual's exposure level to saigas.

In the case of amount pledged for saiga conservation, both wealth and length of time the respondent had been living in the village (residence time) had a positive effect on amount pledged, when controlling for village and intervention, whilst age had a negative influence (Table 7). Higher levels of conservation knowledge strongly increased the amount pledged when no public awareness materials had been received, and remembering having received information led to consistent levels of amount pledged regardless of conservation knowledge. When respondents recalled receiving information, amount pledged for saiga conservation was dependent on an interaction between the date the materials were received and age. For information received between January and October 2006 amount pledged was greatest for those age 26-46. However, if the materials were received in 2005 or earlier, amount pledged was greatest for those aged 18-25 and declined with age.
TABLE 6 Minimum adequate models (fit by GLM with binomial errors) for opinion change over the previous 3 years. When remembering receiving information is an explanatory variable it is significant alongside conservation knowledge. When only those who recalled receiving information were considered, exposure to saigas and the recalled immediate effect of information received were also significant explanatory variables. Conservation knowledge and exposure are ordered factors; remembering receiving information and immediate effect of information received (if respondents recall undergoing a change in awareness on receiving the information) are binomial factors.

\begin{tabular}{lcccc}
\hline & \multicolumn{5}{c}{$95 \%$ confidence interval } \\
\cline { 2 - 5 } Parameter & Estimate & SE & $z$-statistic & $\mathrm{P}$ \\
\hline Positive opinion change with remembering receiving & \\
information as an explanatory variable $(\mathrm{n}=133)$ & \\
Intercept & -0.210 & 0.391 & -0.539 & 0.590 \\
Conservation & 0.568 & 0.196 & 2.893 & $0.004^{* * *}$ \\
knowledge & & & & \\
Remembered receiving & 1.043 & 0.470 & 2.219 & $0.026^{* *}$ \\
information & & & & \\
Opinion change for those who remembered receiving & \\
information (n = 97) & & & & \\
Intercept & -0.882 & 0.796 & -1.109 & 0.274 \\
Exposure to saigas & 1.130 & 0.450 & 2.512 & $0.012^{* *}$ \\
Recalled immediate & 1.766 & 0.712 & 2.481 & $0.013^{* *}$ \\
effect of information & & & & \\
received & & & & \\
\hline
\end{tabular}

${ }^{* *},{ }^{* * *}$, significant at $5 \%$ and $1 \%$, respectively

\section{Discussion}

The results indicate that the population of the north-west Pre-Caspian is, in general, positive about the saiga and its conservation. The Kalmyk people have always held the saiga in high regard and respondents characterized the saiga as 'a symbol of the steppe', 'a beautiful animal' and 'godly creatures'. This attitude provided a positive background for the media campaign, with people already predisposed to be interested in, and respond to, the material provided. Analysis of the public awareness campaign illustrates that in this region media such as newspapers and television are readily available to most of the population and are interested in publishing stories about conservation issues. This may explain why $50 \%$ of interviewees not targeted by the media campaign recalled receiving saiga-related material and illustrates the benefits of using established information delivery systems to provide an effective media campaign. Subject matter was evenly spread across ecology, conservation and poaching and the media campaign was broad and evenly-based, utilizing both written and visual media.

Previous studies have shown that as much as $50 \%$ of the variation in people's attitudes towards conservation can be explained by having received conservation education (Kideghesho et al., 2007). This finding is corroborated by our results, which show that remembering having received 
TABLE 7 Minimum adequate models (fit by LME model with Gaussian errors) for amount pledged for saiga conservation. When remembered receiving information is an explanatory variable it is significant alongside wealth, age, residence time and conservation knowledge. When only those who recalled receiving information were considered, recalled date of receiving the information also became significant. Wealth is continuous; length of time resident in the village (residence time), age, conservation knowledge and date information received are ordered factors; remembers receiving information is binomial. Random effects of intervention and village explained 5.03 and $2.76 \%$ of the variation respectively.

\begin{tabular}{|c|c|c|c|c|}
\hline \multirow[b]{2}{*}{ Parameter } & \multicolumn{4}{|c|}{$95 \%$ confidence interval } \\
\hline & Value & SE & $t$-statistic & $\mathrm{P}$ \\
\hline \multicolumn{5}{|c|}{$\begin{array}{l}\text { Amount pledged for saiga conservation with remembered } \\
\text { receiving information as an explanatory variable }(\mathrm{n}=206)\end{array}$} \\
\hline Intercept & 3.917 & 0.478 & 8.199 & $0.000^{\star * *}$ \\
\hline Wealth & 0.238 & 0.066 & 3.584 & $0.000^{\star * *}$ \\
\hline Age & -0.232 & 0.058 & -3.984 & $0.000^{\star * *}$ \\
\hline Residence time & 0.290 & 0.095 & 3.044 & $0.003^{\star * *}$ \\
\hline Conservation knowledge & 0.404 & 0.140 & 2.877 & $0.005^{\star * *}$ \\
\hline $\begin{array}{l}\text { Remembered receiving } \\
\text { information }\end{array}$ & 0.786 & 0.286 & 2.744 & $0.007^{* * *}$ \\
\hline $\begin{array}{l}\text { Conservation knowledge: } \\
\text { remembers receiving } \\
\text { information }\end{array}$ & -0.358 & 0.153 & -2.338 & $0.020^{* *}$ \\
\hline \multicolumn{5}{|c|}{$\begin{array}{l}\text { Amount pledged for saiga conservation for those who } \\
\text { remembered receiving information }(\mathrm{n}=163)\end{array}$} \\
\hline Intercept & 5.777 & 0.714 & 8.089 & $0.000^{\star * *}$ \\
\hline Wealth & 0.249 & 0.070 & 3.573 & $0.001^{\star * *}$ \\
\hline Age & -0.927 & 0.175 & -3.592 & $0.000^{* * *}$ \\
\hline Residence time & 0.252 & 0.100 & 2.516 & $0.013^{\star *}$ \\
\hline $\begin{array}{l}\text { Recalled date information } \\
\text { received }\end{array}$ & -0.439 & 0.292 & -1.508 & 0.134 \\
\hline $\begin{array}{l}\text { Age: recalled date } \\
\text { information received }\end{array}$ & 0.186 & 0.079 & 2.367 & $0.019^{* *}$ \\
\hline
\end{tabular}

${ }^{* *},{ }^{* *}$, significant at $5 \%$ and $1 \%$, respectively

public awareness materials is a significant variable explaining attitudes. Although it has been suggested that attitudes can be a useful proxy for behaviour in those situations where assessing behaviour is difficult (Infield \& Namara, 2001), most studies are non-committal about the link between the conservation programme being analysed, the resultant attitudes and any reported behavioural changes (Abbot et al., 2001). We used amount pledged for saiga conservation as a measure of behavioural intention but, as giving money for conservation is different from desisting from poaching, the link to behavioural change cannot be made based on these results. However, the propensity for the young to pledge more and the better penetration of the media campaign among men (particularly via television) suggest that young men, the demographic group containing most poachers, may have been effectively reached by the campaign.

A key finding of this study is the importance of reinforcement. Our results suggest that direct exposure to the saiga, to different forms of knowledge and to more intensive conservation interventions serve to reinforce one another, making a change in opinion or behavioural intention more likely to occur. Research on health campaigns has revealed that success is often dependent on whether an issue has been a previous or current concern of the target audience and, in the case of tobacco, whether a person has smoked or not (Glascoe et al., 1998; Pinkleton et al., 2007). It could therefore be useful to use reinforcement strategically within conservation interventions, to effect positive change.

Our study also highlights the importance of understanding the demography and socio-cultural aspects of the focal audience. Taking advantage of factors that may already have raised, or may be able to raise, the receptiveness of the target group is an effective approach. In this region there is an ongoing campaign of raising exposure of the general public to the saiga through visits to the local captive breeding centre and the Stepnoi Reserve. The receptiveness of people who are already regularly exposed to saigas is being exploited by instituting a participatory monitoring scheme focused on those living on remote farms (who also have the most opportunity to poach). There have been few studies in conservation that investigated the effectiveness of using different approaches to public awareness for different target groups and much could be learnt from research in medicine, communication and advertising (Glascoe et al., 1998; Pinkleton et al., 2007).

Our results indicate that media campaigns are effective and can lead to declared positive changes in attitude and behavioural intention. Importantly, through the use of mixed effects models that allowed us to control for confounding factors, we were able to demonstrate that these changes were additional to those occurring in a nearby control population, and that they were reinforced in areas where an additional conservation intervention was taking place. We were also able to place the changes in attitude in time relative to the onset of the campaign, to strengthen the inference that there was a relationship between the campaign and observed attitudinal and behavioural changes. Any changes in attitudes and behavioural intention in the control population of Astrakhan are likely to be the result of receiving public awareness materials by leakage effects and/or confounding variables such as pre-existing knowledge of the saiga and its conservation and exposure level to saigas.

Without effective evaluation at both the case study and global levels conservation will continue to fail to achieve maximum returns on investment (Brooks et al., 2006; Underwood et al., 2009). Evaluating the outcomes of a project is a key requirement of the Darwin Initiative, and this evaluation is a contribution to this requirement. Although this is a case-specific example it demonstrates how an adaptive approach to conservation interventions could increase the effectiveness of ongoing media 
campaigns, to take full advantage of the socio-economic and experiential factors that make people more or less responsive to a particular public awareness programme.

\section{Acknowledgements}

This study was financially supported by ESRC/NERC and the Darwin Initiative (Project EIDPo18). EJMG acknowledges the support of a Royal Society Wolfson Research Merit Award. We gratefully acknowledge the support and advice of Anna Lushchekina, Ruslan Medzhidov, Iuri Arylov and the Centre for Wild Animals of the Republic of Kalmykia, Anatoly Khludnev and the Stepnoi Reserve. We thank Tanya Mudzhaeva and Khongir Mandzhiev for their assistance during data collection, Aline Kühl and Nils Bunnefeld for advice during analysis, and the 250 residents of the study villages for their hospitality and patience in answering our questions.

\section{References}

Авbот, J., Thomas, D., Gardner, A., Neba, S. \& Khen, M. (2001) Understanding the links between conservation and development in the Bamenda Highlands, Cameroon. World Development, 29, $1115-1136$.

Aipanjiguly, S., Jacobson, S. \& Flamm, R. (2002) Conserving manatees: knowledge, attitudes and intentions of boaters in Tampa Bay, Florida. Conservation Biology, 17, 1098-1105.

Ajzen, I. (1991) The theory of planned behaviour. Organization Behaviour and Human Decision Processes, 50, 179-211.

Alix-Garcia, J. (2007) A spatial analysis of common property deforestation. Journal of Environmental Economics and Management, 53, 141-157.

Bateman, I., Carson, R., Day, B., Hanemann, M., Hanley, N., Hetт, T. et al. (2002) Economic Valuation with Stated Preference Techniques. Edward Elgar Publishing, Cheltenham, UK.

Bateman, I. \& Willis, K. (2001) Valuing Environmental Preferences. Oxford University Press, Oxford, UK.

Bernard, H. (2002) Research Methods in Anthropology: Qualitative and Quantitative Approaches. Altamira Press, Walnut Creek, USA.

Brooks, J., Franzen, M., Holmes, C., Grote, M. \& BorgerhoffMulder, M. (2006) Testing hypotheses for the success of different conservation strategies. Conservation Biology, 20, 1528-1538.

Caro, T., Pelkey, N. \& Grigione, M. (1994) Effects of conservation biology education on attitudes towards nature. Conservation Biology, 8, 846-852.

Crawley, M. (2007) The R Book. John Wiley \& Sons Ltd, Chichester, UK.

Fischioff, B. \& Furby, L. (1988) Measuring values: a conceptual framework for interpreting transactions with special contingent valuation of visibility. Journal of Risk and Uncertainty, 1, 147-184.

Glascoe, F., Oberklaid, F., Dworkin, P. \& Trimm, F. (1998) Brief approaches to educating patients and parents in primary care. Pediatrics, 101, e10.

Godoy, R. \& Contreas, M. (2001) A comparative study of education and tropical deforestation among lowland Bolivian Amerindians: forest values, environmental externality and school subsidies. Economic Development and Cultural Change, $49,555-574$.

Grin, F. (2000) Kalmykia: From Oblivion to Reassertion? European Centre for Minority Issues, Flensburg, Germany.

Holmes, C. (2003) The influence of protected area outreach on conservation attitudes and resource use patterns: a case study from Western Tanzania. Oryx, 37, 305-315.

Howe, C., Medzhidov, R. \& Milner-Gulland, E.J. (2011) Evaluating the relative effectiveness of alternative conservation interventions in influencing stated behavioural intentions: the saiga antelope in Kalmykia (Russia). Environmental Conservation, $38,37-44$.

Hungerford, H. \& Volk, T. (1990) Changing learning behaviour through environmental education. Journal of Environmental Education, 21, 8-21.

Infield, M. \& Namara, A. (2001) Community attitudes and behaviour towards conservation: an assessment of a community conservation programme around Lake Mburo National Park, Uganda. Oryx, 35, 48-60.

IUCN (2010) The IUCN Red List of Threatened Species v. 2010.4. Http://www.iucnredlist.org [accessed 6 June 2011].

Kalirajan, K. \& SHAnD, R. (1985) Types of education and agricultural productivity: a quantitative analysis of Tamil Nadu rice farming. Journal of Development Studies, 21, 232-243.

Kideghesho, J., Roskaft, E. \& Kaltenborn, B. (2007) Factors influencing conservation attitudes of local people in Western Serengeti, Tanzania. Biodiversity and Conservation, 16, 2213-2230.

KIRK, R. (1995) Experimental Design: Procedures for the Behavioural Sciences. Brooks/Cole, California, USA.

Kühl, A., Balinova, N., Bykova, E., Esipov, A., Arylov, I.A., Lushchekina, A. \& Milner-Gulland, E. (2009) The role of saiga poaching in rural communities: linkages between attitudes, socioeconomic circumstances and behaviour. Biological Conservation, $142,1442-1449$.

Mehta, J. \& Heinen, J. (2001) Does community-based conservation shape favourable attitudes among locals? An empirical study from Nepal. Environmental Management, 28, 165-177.

Milner-Gulland, E., Kholodova, M., Bekenov, A., Buhreeva, O., Grachev, I.A., Amgalan, L. \& Lushchekina, A. (2001) Dramatic decline in saiga antelope populations. Oryx, 35, 340-345.

Mitchell, R. \& Carson, R. (1989) Using Surveys to Value Public Goods: The Contingent Valuation Method. The John Hopkins University Press, Washington, DC, USA.

Nyhus, P., Tilson, S. \& Tilson, R. (2003) Wildlife knowledge among migrants in southern Sumatra, Indonesia: implications for conservation. Environmental Conservation, 30, 192-199.

OpenStreetMap (2011) Http://www.openstreetmap.org [accessed 22 December 2011].

Palmer, J. \& BirCh, J. (2005) Changing academic perspectives in environmental education research and practice: progress and promise. In Environmental Education and Advocacy: Changing Perspectives of Ecology and Education (eds E. Johnson \& M. Mappin), pp. 114-136. Cambridge University Press, Cambridge, UK.

Parra-Lopez, C., De-Haro-Grumenez, T. \& Calatrava-Requena, J. (2007) Diffusion and adoption of organic farming in the southern Spanish olive groves. Journal of Sustainable Agriculture, 30, 105-151.

Pinkleton, B., Austin, E., Cohen, M., Miller, A. \& Fitzgerald, E. (2007) A statewide evaluation of the effectiveness of media literacy training to prevent tobacco use among adolescents. Health Communication, 21, 23-34. 
R Development Core Team (2008) R: A Language and Environment for Statistical Computing. R Foundation for Statistical Computing, Vienna, Austria. Http://www.R-project.org/ [accessed 14 December 2011].

Underwood, E., Klausmeyer, K., Morrison, S., Bode, M. \& SHAW, M. (2009) Evaluating conservation spending for species return: a retrospective analysis in California. Conservation Letters, 20, 130-137.

UNESCO (UN Educational, Scientific and Cultural Organization) (1992) United Nations Conference on the Environment and Development: Agenda 21. UNESCO, Gland, Switzerland.

VAN, P. (2003) A semiparametric analysis of determinants of a protected area. Applied Economics Letter, 10, 661-665.

Weladji, R., Moe, S. \& Vedeld, P. (2003) Stakeholder attitudes towards wildlife policy and the Benone Wildlife Conservation Area, north Cameroon. Environmental Conservation, 30, 334-343.

\section{Appendices 1-2}

The appendices for this article are available online at http:// journals.cambridge.org

\section{Biographical sketches}

CAROLINE Howe is concerned with how the needs of local communities can be successfully integrated into conservation planning and in exploring methodologies for the quantitative evaluation of conservation outcomes that consider both socio-economic and biological aspects. Olga Овgеnova is the Kalmykian team leader on the Darwin Initiative project 'Evaluating approaches to public engagement in saiga conservation' and provides on the ground support for saiga conservation in Kalmkyia. E.J. Milner-Gulland has a broad interest in the relationship between human decision-making and conservation success and is Chair of the Saiga Conservation Alliance (http://www.saiga-conservation.com). 